\title{
Cultural Transfer as an Obstacle for Writing Well in English: The Case of Arabic Speakers Writing in English
}

\author{
Dr. Ruwaida Abu Rass \\ The Academic Arab Institute for Teachers' Training at Beit Berl College \\ Tel: 97-298-783-526Ｅ-mail: aburass@beitberl.ac.il
}

Received: September 19, 2010 Accepted: November 23, 2010 doi:10.5539/elt.v4n2p206

\begin{abstract}
This paper reviews and strengthens the data on cultural transfer by Arab Muslim students writing in English and adds the significant element of the cultural impact of Islam on such writing. This qualitative study examines the writing of 18 teacher trainees at an Arab language teacher training college in Israel. Results point to a strong cultural influence appearing in the students' writing. It is suggested that greater consideration should be given to the first and the target culture when designing the curricula for writing classes for Arab L1 students in English writing instruction.
\end{abstract}

Keywords: Cultural transfer, Writing in English, Arab Islamic culture

\section{Introduction}

Writing in English is especially difficult for non-native speakers because they are expected to produce native-like written products (Casanave, 2003). Since Kaplan's seminal study in 1966, the field of contrastive rhetoric has developed and investigated the influence of L1 on L2 writing. According to Kaplan, "Rhetoric . . . is not universal . . ., but varies from culture to culture. .." (p. 2). He claimed that the thought patterns which speakers of English appear to expect is a "sequence that is dominantly linear in its development" (p. 4). However, he found that the Arab students in his study used a paragraph development based on a complex series of parallel constructions, both positive and negative. According to Allen's observation (1970), the organization of the text of Arabic is "circular and non-cumulative," and "Arab writers come to the same point two or three times from different angles so that a native English reader has the curious feeling that nothing is happening" (cited in Sa'adeddin, 1989, p. 36). In contrast, the text in English is expected to be linear, coherent and concise (Sa'adeddin, 1989). Derrick and Gmuca (1985) argue that there is no room for doubt in Arab students' writing.

Conner (2002) claims that the current approaches to contrastive rhetoric have explained that the differences in L2 writing derive from "multiple sources, including L1, national culture, L1 educational background, disciplinary culture, genre characteristics and mismatched expectations between readers and writers" (p. 504).

Ferris (2001) maintains that "It is important for theorists and teachers to understand that significant differences exist across L2 contexts and populations" (p. 299). This present study is aimed at better understanding the differences in such context and this population and to address these differences in writing pedagogy. Although a number of researchers have written and spoken about the writing problems of Arab students in the past, cultural interpretation has not been sufficiently addressed. The purpose of this study is to add to the body of knowledge concerning the influence of Arabic L1 and Muslim culture on L2 English writing. It offers specific suggestions for instruction and reports on the success of these instructional methods in closing the gap between L1 influenced English writing and standard academic English writing. These suggestions would be useful for helping native English speaking instructors of writing understand the errors of their Arab students. Moreover, this paper would promote multiculturalism which is the prevailing reality in the modern world.

\section{Cultural transfer}

Cultural transfer is likely to happen when students learn to write in English as a second or foreign language because their behavior is influenced by their first culture: the first culture saturates the L2 writing experience and influences its product as well. However, the specifics of cultural influence on writing have rarely studied. There have been some studies that investigated other areas of cultural influence. For example, Fillmore, Ammon, McLaughlin, and Ammon (1993) conducted a study of Chinese and Hispanic students learning English in the United States to see the effectiveness of the communicative approach on different group learning styles. They found that Chinese students prefer teacher directed environments of learning that are tightly controlled. In contrast, Hispanic students favor 
"group centered, cooperative learning in somewhat more open, socially-oriented classroom environments" (Fillmore et al, 1993, p. 18). In addition, Mauranen (1993) claims that it is fair to assume that culture influences writing habits and cultural variances exist not only among highly different cultures but also the close ones. In a comparison between Finnish and Anglo-American texts, she concludes that they employ different rhetorical preferences in their writing which are influenced by their first cultures. For example, the Finnish discourse does not prepare the reader for what to expect and the conclusion. In contrast, the Anglo-American writers appear to show more awareness of the audience.

As a result of cultural transfer, Arab students fail to consider audience in their mind when they write in English (Abu Rass, 1994). According to Khuwaileh \& Shoumali, (2000) Arab students "usually think and prepare their ideas in their native language and then translate them into English" (p. 174). A study conducted by Al-Khatib (2001) about writing personal letters in English by Arab Jordanian students shows that the students transferred the Arabic style of writing personal letters into English and the used language reflects the Arab cultural thought patterns which has been characterized by length and indirectness. For example, "the introductions are lengthy in terms of questioning (not concise) and are not to the point" (Al-Khatib, 2001, 188). They might include questions about the addressee's health, personal life and family. In contrast, the British people do not include such questions in their personal letters. Al-Khatibeb concludes that the style of writing letters by these subjects is clearly affected by their sociolinguistic backgrounds without taking into consideration the sociolinguistic of the addressee. Reviewed research by Feghali made her to conclude that speakers of Arabic share the following common features of communicative style which may conflict with other language styles: (a) repetition, (b) indirectness, (c) elaborateness, and (d) affectiveness which means intuitive-affective style of emotional appeal.

\subsection{Influence of religion, Islam}

Al-Khatib (1994) cites Abdulati (1975) who claims that "the authenticity of the Qura'n for Moslems is beyond doubt" (12). Moslems usually accept principles covered in the Qura'n as Divine truth and reject others that differ from the Qura'nic principles and teachings, which embrace all aspects of life. Feghali (1997) cites Glisenan (1983) who claims that swearing oaths on the Qura'n and the Prophet Muhammad are part of the Arabic discourse. "Belief in God has direct and ultimate control of all that happens" (Nydell, 1987, 34).

Abu Rass (1994) indicated that the Arabic culture is highly influenced by Islam, which is based on the main principle of unity of belief in God and the prophet Muhammad. As a result, Arab students have the tendency to use dichotomy: solutions to problems are black or white, right or wrong. In other words, there is no room for doubt or compromise. Questioning the norms or the ultimate truth is rare in the Arabic culture. The writer assumes that the reader is in complete agreement with him because of cultural consensus. In addition, Arab culture adheres and promotes collectivism rather than individualism (Feghali, 1997)."The loyalty to one's extended family and larger "in-group" takes precedence over individual needs on goals" (Feghali, 1997, 352). Therefore, Arabic speakers are more group oriented and tend to use pronouns that express collectiveness such as "we" and "us".

In Al-Khatib's study, religion was found to play a role in the process of letter writing. For instance, religious expressions such as "In the name of God", the beneficent, and the Merciful" are used heavily used on the top of the letters. In addition, the expression "God willing" is used to express the writer's wish for something good to happen in the future. Similarly, Feghali (1997) mentions that Arabs tend to use proverbs and ritual phrases to express complementation. However, language reformers call for more precision and simplicity in Arabic rhetoric (Feghali, 1997).

\subsection{Repetition and exaggeration for the sake of persuasion}

Supporting the argument is done by quotations of verses from the Qura'n, the holy book, and sayings of Prophet Muhammad (Ahadeeth) as well as citing of prominent leaders or Islamic scholars (Abu Rass, 1994). "Repeated words, phrases and rhythms move others to belief, rather than the "quasilogical" style of Western logic, where interlocutors use ideas to persuade" (Feghali, 1997. 361). Johnstone (as cited in Feghali, 1997)) suggests that persuasion is most often employed in cultural settings "in which religion is central, settings in which truth is brought to light rather than created out of human rationality" (p. 151). Therefore, Arabic speaking students of English tend to copy verses from the Qura'n to convince their readers because they believe that the text is infallible in content and literary style. As a result of following the style of the Qura 'n, presenting different perspectives for argumentation doesn't exist in the Arabic prose. Students are not expected to challenge what is socially validated, especially if it is mentioned in the Qura'n. For example, male and female segregation should not be questioned because it is mentioned explicitly in the Qura'n.

Using rich and expressive language is another characteristic of elaboration among Arabic speakers (Feghali, 1997). In addition, exaggeration and assertion are other two rhetorical patterns of the Arab communicative style. So Arabic 
speaking tends to exaggerate and over-assert things to be believed and understood. Feghali cited Adelman \& Lustig (1981) who conducted a survey among Saudi Arabian and American managers to identify elaborateness. The responses of that survey show that American managers believed that their Saudi counterparts had problems in expressing their ideas in a clear concise way. The findings of the above cited research show that American managers perceived the Saudi managers had difficulty in displaying objectivity in decision-making.

Al-Khatib (1994) claims that persuasion in Arabic is structural and rule-governed. It is based on three major modes: trustworthiness, argumentation and appeal to emotions. These modes are based on reason and emotions. First, persuaders try to convince the audience by asserting their trustworthy and reliability. Second, they attempt to persuade others by argument providing opinion and supporting it by giving convincing reasons. Third, persuaders may appeal to the audience emotionally. It is usually used through the use of religion and religious devices and the use of proverbs and wisdoms. Religious devices mean the use of some Qura'nic verses. The use of proverbs and wisdoms refers to the sayings and lines of the verse. Al-Khatib's study reveals that these three modes work together.

\section{Methodology}

\subsection{Subjects and context}

The subjects of the research were first year students in the English Department in the Academic Arab Institute for Teacher Training at Beit Berl College. The Arab Institute is a four-year Arab language teacher training college located in the center of Israel. Upon graduation, students receive a Bachelor degree and teacher certification. All students in the institute are Muslims. The first year class consisted of 18 female students. These students participated in a four-hour compulsory course which emphasized proficiency in writing in terms of content and organization. The main objective of the course was to enable students recognize a well-written paragraph in English and to provide them with the techniques necessary to write such a paragraph. The students wrote ten paragraphs during the semester. To achieve proficiency in writing, the students were required to write each paragraph three times. Drafting, revising and editing were the three main stages for developing the required paragraphs. The instructor responded mainly to the content and organization by asking questions or writing comments such as "What do you mean?" or "An example is necessary." In addition, six free writing journals were required throughout the course. The topics were chosen by the students who were expected to write about their feelings and experiences. Complaints or suggestions for class work were also recommended as topics for journals. At the end of the school year, the students collected their writings into a portfolio for evaluation. This portfolio included all their drafts, their favorite journal and evaluation of their work and progress.

\subsection{Data Selected for Analysis}

The first step was collecting the students' portfolios which were part of the class requirements. The second step was collecting all the sheets of error analysis that had been collected from the students' samples by the writing instructor throughout the year for class discussion. Error analysis exercises included authentic student writing which would illuminate common problems and errors, which stem from the influence of the first culture.

\subsection{Analysis Procedure}

Qualitative research methods were employed to have a deep insight of the influence of the first culture on the writing of Arab students in English. Two samples were selected from each student from the portfolios. The first paragraph was assigned prior to any kind of instruction. The topic concerned their expectations as freshmen at Beit Berl College as a teacher training institute. The focus of the second paragraph was providing examples to support their topic sentences. The topics were varied because they were asked to choose a topic from the recommended list at the end of their text chapter. This assignment was given at the end of the first semester. The researcher analyzed the data in terms of form and content. Categories were established for analyzing the writing mistakes and problems that stem from first cultural transfer. These categories are the following: repetition and exaggeration, unity of belief, group orientation, bi-polarity and transmission of material. Then the researcher looked for generalizations. For example, if the subjects' samples of writing were culturally inappropriate and unacceptable in North America, they are listed under the cultural category.

\section{Results}

\subsection{Repetition and exaggeration}

Koch (1083) claims that Arabic speakers argue by "repeating arguments, paraphrasing them and doubling them" (p.500) The following student paragraph, for example, illustrates some of these elements:

I must admit for that I wanted so much to learn in English department and I always loved the English language, but when I started learning I found out that it's not so easy as I expected, it's very different from school, the material is 
difficult, the teachers are more serious, much more hours learning and doing homeworks a lot of homeworks, but I am not complaining., I will just do my best, I entered a new world which it's not easy, it's not what I expected to be, for example, I always looked at English as a simple language, but I discovered it's not one thing, English is a big world you have to learn many topics and things in English such as poetry, academic writing/reading, grammar, writing...it's just complex and complicated, it's so different from what I learnt in school I don't know why? Maybe because I wasn't good enough or the teachers weren't good enough.

Arab students tend to write long and expanded English sentences with repetition of content and form. In Arabic, repeating ideas and phrases is used for the sake of persuasion. Repetition is presented by writing more synonyms in the same sentence to convey emphasis. In class, paragraphs such as the above would be used for discussion and for highlighting the differences in standard English rhetoric and Classical Arabic rhetoric.

Error analysis included cultural interpretation. The instructor usually challenged the inappropriate use of words and their implications. For example, the following paragraph shows fewer language problems, but is an example of the cultural influence on writing:

Fortunately, I achieve to be a freshman like I dreamed before. I expect a lot from my college. Firstly, I do believe that it will teach me to be the best English teacher in the future because of the different methods we will be taught. Secondly, I hope that I'll get more and more encouragement to work harder to reach my goals, like to be the friendly teacher. Thirdly, I'm sure that this college will push us forward step by step to understand our pupils and make good relationship with all of them in order to be the closest friend for each of them. Lastly, this college is the best one for me and I'm sure it will give me a lot as my feelings tell me.

In the paragraph above, the writer has less repetition and, more importantly, she has a thesis statement which she supports with some ideas. However, the use of superlatives in her writing has interesting cultural implications. She wants to be "the best English teacher:; she wants to be "the friendly teacher"; she wants to be the closest friend; and "this college is the best one for me. "The use of superlatives indicates a unity of belief, indicating that there is only one true path to becoming a successful teacher. In addition it reflects exaggeration and assertion.

\subsection{Group orientation}

An indication of the group oriented culture is reflected in the students' use of the possessive pronouns "us" and "our" to express their feelings or wishes. The following two examples from the first assignment reflect this tendency:

(1).It will teach us how to be the best English teachers in the future because of the different methods we will be taught ..."

(2).We've faced all the materials we are going to learn for the rest of the year. I'm just hoping that we will success.

\subsection{Unity of belief}

The category unity of belief means the straight path. There is only one way, one path for Muslims.

The following examples illustrate the category of unity of belief. One religious student systematically wrote "under the name of God" on the top of her written work. Another student mentioned at the end of her paragraph that she will succeed, "God willing". The following examples of unity of belief were also quoted from three other student samples.

(1).So, my request from God is to gather me and my family with our lovely prophet in paradise

(2).Very suitable for me and other students as Arabs

(3).I do believe that it will teach us how to be the best English teachers in the future

(4).I hope to be a successful student and a competent freshman at Beit Berl College, God Willing.

\subsection{Bi-polarity}

Because there is only one belief, a dichotomy is set up for all aspects of life; things belong o one extreme or another. The following are examples of bi-polarity were taken from the first assignment (their expectations as freshmen at the college):

(1).I expect first of all to be treated right, to have good education and right instruction

(2).Lastly, this college is the best one for me, the best English teacher.

(3).I expect unique teachers.

(4).I expect to be provided by all the requirements.

(5).I expect to pass all the exams and overcome the difficulties. 
(6).I hope get excellent marks and become excellent teachers.

(7).I expect from myself to be a successful student.

(8).If I need any help, I can ask the lecturer and he or she will show me the right...

(9).I am sure that I will be a successful teacher.

(10).I think this college will teach us how to be an ideal teacher. Also to teach me how to be more serious because I think it is the right way for a successful teacher, to be an ideal for my students,

The choice of vocabulary in the above mentioned examples reflect the tendency of the students of using dichotomy and assertion in their writing. The words all, best and ideal show the bi-polarity in the writing of the Arab students. They demonstrate the students' belief that there is one right way; there is a single answer; there is black and white and no shades of grey. They also show the tendency of exaggeration and assertion rather than simplicity.

\subsection{Transmission of material}

Since Muslims do not contrast their truth or their beliefs, they are expected to follow the straight path and they expect to be given the truth from their instructors and elders rather constructing knowledge from different sources of materials. As a result, there is the expectation to be provided with materials, ideas, and methods. Teachers are expected to be the source of knowledge and transmit it to the students. The students' responsibility is to accept rather than construct knowledge. These examples show the way of thinking of Arab students who believe in being receptive rather than constructive.

(1) I'll get a very big treasure of knowledge from all of the teachers.

(2) My first day at BBC with nice impression to find all my needs.

(3)Beit Berl College as an Arab institute will teach us how to control the class

(4) I expect the teachers to give us new and different information about our subject.

(5) The college will teach us how to be an ideal teacher

(6) I expect from it to teach me the best and to give me more and more to make me be ready for the message that they want to give me...

The students are not expecting to be exposed to different strategies, techniques, methods of teaching and choose what is appropriate for their style of teaching and the needs of their students. Rather, they expect to be told what to teach and how to teach.

The examples above represent the five categories presented for data analysis: repetition and exaggeration for the sake of persuasion, group oriented, unity of belief, bi polarity and transmission. The data are meant to give a picture of the influence of culture on the English writing of Muslim Arabic L1 students writing in English.

\section{Discussion}

The examination of the paragraphs led the researcher to assume that there is evidence of influence of Arabic culture in the students' English writing. In their writing, I found that Arab students have the tendency for exaggeration, assertion and group orientation. They also demonstrate their unity of belief, their tendency towards dichotomous thinking and their belief in a one right way or a single true path. These results correlate with the claims of Abdulati (1975) cited in Al-Khatib (2001) and Abu Rass (1994). Besides, the tendency for exaggeration, assertion and group orientation is also evident in their writing. These cultural patterns prove the claims of Al-Khatib (2001 \& 1994), Feghali (1997) and Khuwaileh \& Shoumali (2000) about cultural transfer in the writing of Arab learners into English.

The researcher's observations correlate with Derrich \& Gmuca (1985) who argue that there is no room for doubt in Arab students' writing. In fact, they try to present the ultimate truth in their writing. Since the Arabic-Islamic culture is based on the unity of belief, a diversity of beliefs, ideas and perspectives is not valued (Glisenan, 1983; Johnstone, $1989 \&$ Nydell, 1987). The extensive use of "God willing" and "In the name of God" shows that religion is the core for all paths and aspects of life among Muslims (Al-Khatib 2001 \& 1994 \& Feghali, 1997). In addition, it reflects the emotional appeal in the writing of the students.

This style of writing causes another problem for Arab students who often fail to consider the idea of "audience" when they write. The students usually assume that the reader understands them without giving examples. Because there is no room for doubt in Arab students' writing, it follows that the writer and the audience agree on the validity of a viewpoint even before the essay is written. The analysis of the students' samples of errors go in line with the claims of Abu Rass (1994) \& Glisenan, 1983 cited in Feghali, 1997). 
The Arabic culture is patriarchal and hierarchical; therefore, students expect teachers to spoon feed them rather than challenge their minds Since they believe that authority comes from above, they expect instructors to transmit materials for them rather than help them to construct their meanings.

\section{Implications for teaching}

Today there is an expanding focus on multiculturalism. Educators are asking questions about the influence of culture of classroom practice and searching for answers to these questions. Firstly, they wish to improve their classroom practice, but more importantly, they wish to facilitate clear communication. In a world in which English is the main means of communication for literally millions of non-native speakers, any research which could further this goal is welcome and important.

\subsection{Language awareness discussion}

I suggest the use of language awareness discussion to familiarize our students with the differences of L1 writing and the accepted norms of standard English academic writing. For example, the writing teacher may start his instruction with a discussion of elements in L1 writing. This could be done by brainstorming or writing what makes L1 writing good. The elaborated discussion should include what makes L2 writing good too.

\subsection{Acquainting the writing instructors with the culture of their students}

The results of this research made the researcher to conclude that it is recommended that ESL/EFL writing teachers may review some literature about Arabic-Muslim culture and its effect on Arab student writing. By reading the relevant materials about Arabic culture, they would be aware of their students' cultural background.

\subsection{Text analysis}

Text analysis might also be helpful here. Instructors may analyze short paragraphs to show Arab students the thesis sentence and how it is supported by other sentences. Repetition and elaboration would be reduced by exposing Arab students to more texts in English. It means that Arab speaking learners of English might be required to read more to acquire the code of writing in English. To help Arab students improve the content of their writing, writing instructors should not treat all genres of writing equally. Time and effort should be devoted more to unfamiliar genres such as argumentation and persuasion. Focusing on oral discussion before starting any writing assignment is appropriate for Arab students since they come from an oral culture. This may provide a clearer idea about what they are expected to write.

\subsection{Cultural interpretation}

Cultural interpretation and explanation would also be useful. Cultural explanation is useful to familiarize the learners with the target culture. For example, it might be necessary to expose the learners to Western family issues in the English speaking countries. In general, these are different from the Arabic culture. The latter culture is more patriarchal, community oriented and high context. In contrast, the former one is based on more equality between the sexes, individualism and is low context. There is little consensus over any issue. It is also important to familiarize the learners with the academic culture which is based on critical thinking.

Today with the expanding focus on multiculturalism, researching such patterns is important. Recognition and classification of what are considered to be non-standard English patterns are important first steps in the teaching process. Firstly, it can raise the awareness of instructors. Second, it can allow for focused instruction. As Hinkle (2002) has pointed out, because Anglo-American readers are often vested with the power of evaluating the quality of NNS [non-native speaker] writing, the mismatch in NS [native speaker] and NNS accessible knowledge places L2 writers in a bind that cannot be easily overcome" (p. 4). Expansion of knowledge in this field can have important implications for education in Israel and in the world.

\section{Conclusion}

Arab culture is ancient and deep. It is also the product of a given geographical area and strongly influenced by one religion-Islam. On the other hand, the English language transverses boundaries and borders, religion and cultures. However, English language writing does have roots and traditions that are generally accepted and respected by users all over the world.

The present research reveals that many problems that Arab learners of English face stem from cultural transfer. First cultural interference is an obstacle for Arab students in acquiring English academic writing proficiency. The main conclusion is that greater consideration should be given to culture when designing language programs. L1 is certainly an important influence, but recognition of culture and ethnicity can lead to greater student success through consideration, understanding and acceptance. 
Note: $20 \%$ of Israel's citizens are Arab; $93 \%$ are Muslims, and $7 \%$ are Christians. All of the students in the study are Muslims.

\section{References}

Abdulati, H. (1975). Islam in Focus. Cited in Al-Khatib, M. (2001). The pragmatics of letter writing. World Englishes, 20 (2), 179-200.

Abu-Rabia, S. (1995) Multicultural and problematic social contexts and their contribution to L2 learning. Language, Culture and Curriculum, 8 (2), 183-199.

Abu Rass, R. (1994) The effect of Arabic Culture on Arab Students' Writing. Unpublished Seminar Paper. University of Arizona, Tucson, Arizona.

Al-Khatib, M. (2001). The pragmatics of letter writing. World Englishes, 20 (2), 179-200.

(1994). A sociolinguistic view of the language of persuasion in Jordanian society. Language, Culture and Curriculum, 7 (2), 161-174.

Casanava, C.P. (2003) Looking ahead to more sociopolitically-oriented case study research in L2 writing scholarship (But should it be called "post-process"?) Journal of Second Language Writing 12, 85-102.

Conner, U. (2002) New directions in contrastive rhetoric. TESOL Quarterly. 36(4). 493-510.

Derrick, M.M. \& Gmuca, J.L. (1985) Concepts of unity and sentence structure in Arabic, Spanish and Malay. Paper presented at the annual meeting of the conference on college composition and communication, (36th, Minneapolis, MN, March 21-23).

Feghali, E. (1997). Arab cultural communication patterns. International Journal of Intercultural Relations, 21 (3), 345-378.

Fillmore, L. W., Ammon, P., Mclaughlin, B., Ammon, M.S. (1993). Learning English through bilingual instruction: Executive summary and conclusion. LRC 525, University of Arizona, 1-35.

Ferris, D.R. (2001). Teaching writing for academic purposes. In Flowerdew, J. \& M.

Peacock. Research perspectives on English for academic purposes. Cambridge: Cambridge University Press. Pp 298-314.

Gilsenan, M. (1983). Recognizing Islam: Religion and society in modern Arab world. Cited in Feghali, E. (1997). Arab cultural communication patterns. International Journal of Intercultural Relations, 21 (3), 345-378.

Johnstone, K. B. (1989). Presentation as proof. The language of Arabic Rhetoric. Anthropological Linguistics, 25 (1), 47-60.

Kaplan, R.B. (1966). Cultural thought patterns in intercultural education. Language Learning. 16(1 \& 2), 1-20. .

Khuwaileh, A.A. \& Shoumali, A.A. (2000). Writing errors: A study in writing ability of

Arabic learners of academic English and Arabic at university. Language, culture and curriculum. 13(2). 174-183.

Mauranen, A. (1993). Contrastive ESP rhetoric: Metatext in Finnish-English economics texts. English for Specific Purposes, 2 (3), 3-22.

Nydell, M. (1987). Understanding Arabs: A guide for Westerners. Yarmouth, ME: Intercultual Press.

Sa'adeddin, M.A. (1989). Text development and Arabic-English negative interference. Applied Linguistics. 10 (1). Pp.36-51. 